\title{
Rapid, ultraviolet-induced, reversibly switchable wettability of superhydrophobic/superhydrophilic surfaces
}

\author{
Yunlu Pan ${ }^{1}$, Wenting Kong ${ }^{1}$, Bharat Bhushan ${ }^{* 1,2}$ and Xuezeng Zhao ${ }^{* 1}$
}

\author{
Full Research Paper \\ Address: \\ ${ }^{1}$ Key laboratory of Micro-Systems and Micro-Structures \\ Manufacturing of Ministry of Education and School of Mechatronics \\ Engineering, Harbin Institute of Technology, Xidazhi 92, Harbin, \\ 150001, PR China and ${ }^{2}$ Nanoprobe Laboratory for Bio- \& \\ Nanotechnology and Biomimetics (NLBB), The Ohio State University, \\ 201 W. 19th Avenue, Columbus, OH 43210-1142, USA \\ Email: \\ Bharat Bhushan* - bhushan.2@osu.edu; Xuezeng Zhao* - \\ zhaoxz@hit.edu.cn \\ * Corresponding author \\ Keywords: \\ superhydrophilic surfaces; superhydrophobic surfaces; switchable \\ wettability; $\mathrm{TiO}_{2}$; trimethoxy(alkyl)silane; UV illumination \\ Beilstein J. Nanotechnol. 2019, 10, 866-873. \\ doi:10.3762/bjnano.10.87 \\ Received: 26 November 2018 \\ Accepted: 08 March 2019 \\ Published: 15 April 2019 \\ Associate Editor: N. Motta \\ (C) 2019 Pan et al.; licensee Beilstein-Institut. \\ License and terms: see end of document.
}

\begin{abstract}
Controllable wettability is important for a wide range of applications, including intelligent switching, self-cleaning and oil/water separation. In this work, rapid switching and extreme wettability changes upon ultraviolet (UV) illumination were investigated. $\mathrm{TiO}_{2}$ nanoparticles were modified in solutions of trimethoxy(alkyl)silane, and the suspensions were sprayed on glass substrates. For such samples, the water contact angle (WCA) was shown to transition from a superhydrophobic (WCA $\approx 165^{\circ}$ ) to a superhydrophilic $\left(\mathrm{WCA} \approx 0^{\circ}\right.$ ) state within 10 min upon UV illumination and subsequent recovery to superhydrophobicity occurred after heat treatment. It was found that the changes in the trimethoxy(alkyl)silane upon UV illumination can explain the rapid decrease of the WCA from more than $165^{\circ}$ to almost $0^{\circ}$. To further investigate the wettability transition, trimethoxy(alkyl)silane and $\mathrm{Al}_{2} \mathrm{O}_{3}$ nanoparticles (which are not photocatalytic) were mixed and spray-coated onto the glass substrates as the control samples. Then the unrecoverable change of trimethoxy(alkyl)silane under UV illumination can be confirmed. It was found that the presence of trimethoxy(alkyl)silane in the $\mathrm{TiO}_{2}$-trimethoxy(alkyl)silane coating served to speed up the super-wettability transition time from superhydrophobicity to superhydrophilicity, but also limited the number of wettability recycle times. With this understanding, the effect of the trimethoxy(alkyl)silane concentration on the number of recycle cycles was investigated.
\end{abstract}

\section{Introduction}

Wettability is an important property of solid surfaces governed by surface chemistry and surface topography $[1,2]$ and has found significant applications in various fields [3-8]. Control- lable wettability that can be enabled through external stimuli, such as illumination, electric fields or heating, can be applied in chemical sensors, smart filtration and separation, and micro- 
fluidic devices [9-12]. While controlling wettability through heating is mostly limited to toxic materials, such surfaces cannot be applied in human science [13,14]. Although the application of an electric field is an efficient method to achieve switchable wettability, the range of variation in the wettability is still limited $[15,16]$. Among the numerous approaches to achieve switchable wettability, UV illumination is highly preferred due to its environmentally friendly, non-contact and convenient manner. $\mathrm{TiO}_{2}$ nanoparticles are a common photocatalysis material that has attracted attention since it is more sensitive to UV light [17]. The use of a photochemical method to strengthen the interaction between nanoparticles and organic materials is quite common $[18,19]$. $\mathrm{TiO}_{2}$ nanoparticles modified with organic materials that have a low surface energy could be used to induce the property of switchable wettability under UV illumination.

In order to be useful for many applications, the ability to rapidly switch the wettability from superhydrophobicity to superhydrophilicity is imperative. Several studies based on $\mathrm{TiO}_{2}$ have been carried out to prepare surfaces exhibiting reversible wettability [20]. Wang et al. [21] prepared a $\mathrm{TiO}_{2}$ polycrystalline film which achieved drastic changes in wettability when the water contact angle (WCA) was changed from $72^{\circ}$ and $0^{\circ}$ under UV illumination, followed by recovery at around $70^{\circ}$ after storing in the dark. Jin et al. [22] modified $\mathrm{TiO}_{2}$ with 7-[4-(trifluoromethoxyphenylazo)phenoxy]pentanoic acid $\left(\mathrm{CF}_{3} \mathrm{AZO}\right)$ which could reversibly switch between hydrophobic $\left(\approx 145^{\circ}\right)$ and hydrophilic $\left(\approx 24^{\circ}\right)$ under UV illumination for about $13 \mathrm{~h}$. Chagas et al. [23] fabricated surfaces that were reversibly wettable by dipping polypropylene surfaces in a suspension of $\mathrm{TiO}_{2}$ modified with trimethoxypropyl saline. In this work, the wettability transition time from superhydrophobic $\left(\mathrm{WCA} \approx 158^{\circ}\right.$ ) to superhydrophilic (WCA $\approx 0^{\circ}$ ) occurred within $120 \mathrm{~min}$ of UV illumination.

Although large range wettability switching can be achieved in many ways, the transition from superhydrophobic to superhydrophilic always requires a longer time, ranging from a couple of days to a couple of hours [23-27]. Some studies have been carried out to reduce the wettability transition time. Sawada et al. [28] fabricated surfaces with $\mathrm{TiO}_{2} /$ fluoroalkyl end-capped vinyltrimethoxysilane sol-gel where the WCA changed from about $180^{\circ}$ to $108^{\circ}$ in under $50 \mathrm{~min}$ upon UV illumination and then further reduced to $20^{\circ}$ after another $30 \mathrm{~min}$. Thus the total transition time from superhydrophobic to superhydrophilic was about 80 min. Petroffe et al. [29] modified $\mathrm{TiO}_{2}$ with 11-(4(phenylazo)phenoxy)undecanoic acid (AzoC11) acid to fabricate a hybrid surface which could achieve a rapid change in wettability properties within $12 \mathrm{~min}$, however the wettability range was only between hydrophobic $\left(\approx 146^{\circ}\right)$ and hydrophilic $\left(\approx 21^{\circ}\right)$. Qing et al. [30] fabricated superhydrophobic $\mathrm{TiO}_{2}$ nanoparticles with (heptadecafluoro-1,1,2,2-tetradecyl)trimethoxysilane, which not only exhibited reversible wettability from $160^{\circ}$ to $0^{\circ}$ but also reduced the transition time to $60 \mathrm{~min}$.

By modifying trimethoxy(alkyl)silane, $\mathrm{TiO}_{2}$-based surfaces can achieve a faster change from superhydrophobic to superhydrophilic. However, the reason of the faster transition process has not explained. Due to the high energy of UV illumination and the photocatalysis effect of $\mathrm{TiO}_{2}$, the $-\mathrm{CF}_{2-},-\mathrm{CF}_{3}$ groups of the modified trimethoxy(alkyl)silane might become photodegraded and the end of the trimethoxy(alkyl)silane would change into $-\mathrm{OH}$ groups without reversibility [31,32]. It can then be assumed that the degradation of trimethoxy(alkyl)silane could reduce the transition time from superhydrophobic to superhydrophilic for surfaces modified with $\mathrm{TiO}_{2}$ nanoparticles and trimethoxy(alkyl)silane.

In this study, to confirm this assumption, a series of experiments were carried out. Surfaces were coated with $\mathrm{TiO}_{2}$ nanoparticles and non-photosensitive $\mathrm{Al}_{2} \mathrm{O}_{3}$ nanoparticles as the control groups, respectively. The nanoparticles were modified with a short carbon chain trimethoxy(alkyl)silane, $1 \mathrm{H}, 1 \mathrm{H}, 2 \mathrm{H}, 2 \mathrm{H}$-perfluorooctyl(trimethoxy)silane (PFOS), in different concentrations. The wettability and the chemical bonding of the surfaces were tested upon UV illumination and heating treatments. The results are in agreement with the proposed assumption that the oxidization of the trimethoxy(alkyl)silane could decrease the super-wettability transition time, however the reversibility will be limited due to the irreversible oxidization process. The effect of trimethoxy(alkyl)silane concentration on the number of times the surface can be recycled was also investigated.

\section{Results and Discussion Characterization of the superhydrophobic coating}

The hydrophilic $\mathrm{TiO}_{2}$ nanoparticles were modified in ethanol solutions of PFOS, and the suspensions were sprayed on glass substrates to make the $\mathrm{TiO}_{2}-\mathrm{PFOS}$ samples. With the same method, $\mathrm{Al}_{2} \mathrm{O}_{3}$-PFOS samples were prepared as control groups. As shown in Figure 1, both $\mathrm{TiO}_{2}-\mathrm{PFOS}$ and $\mathrm{Al}_{2} \mathrm{O}_{3}-\mathrm{PFOS}$ coated surfaces exhibited excellent superhydrophobicity, and the WCA was measured as about $165^{\circ}$ and $171^{\circ}$, respectively. Based on the SEM images shown in Figure 1, two-dimensional micro-nanostructures can be obviously seen on the two kinds of surfaces due to the aggregation of nanoparticles, which can explain the good superhydrophobicity.

The $\mathrm{TiO}_{2}$ nanoparticles were subjected to chemical bonding as $\mathrm{Si}-\mathrm{O}-\mathrm{Ti}$ with hydrolysing PFOS. The chemical bonding is veri- 


\section{$\mathrm{TiO}_{2}$ - PFOS Composite}

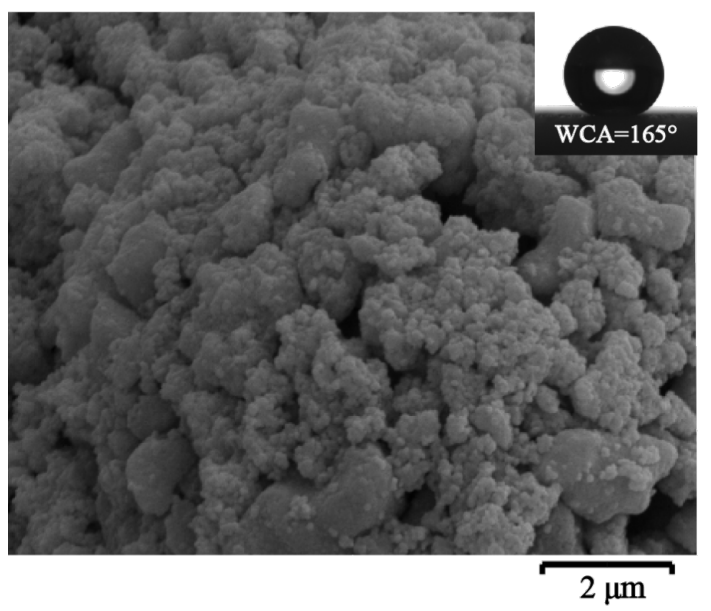

$\mathrm{Al}_{2} \mathrm{O}_{3}$ - PFOS Composite

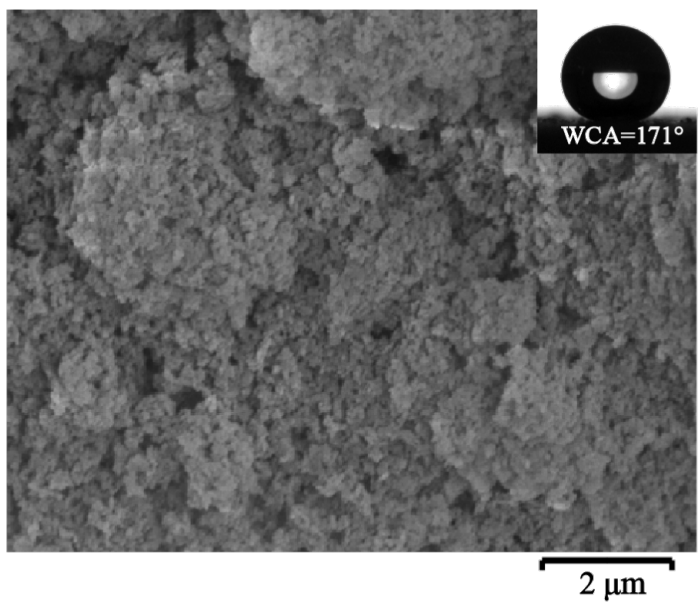

Figure 1: SEM images of $\mathrm{TiO}_{2}-\mathrm{PFOS}$ and $\mathrm{Al}_{2} \mathrm{O}_{3}-\mathrm{PFOS}$ composite surfaces.

fied by the Fourier transfer infrared (FTIR) spectra of $\mathrm{TiO}_{2}$ and $\mathrm{TiO}_{2}-\mathrm{PFOS}$ coated glass surfaces, as shown in Figure 2. The asymmetric stretching vibration of the $\mathrm{Si}-\mathrm{O}-\mathrm{Ti}$ species was displayed at the absorption peak of $1065 \mathrm{~cm}^{-1}$ which further confirmed the dehydration reaction occurred between the hydrolytic PFOS and $\mathrm{TiO}_{2}$. Additionally, there were another three peaks at $1157,1207,1243 \mathrm{~cm}^{-1}$, which correspond to the stretching vibration of $-\mathrm{CF}_{2-}$ and $-\mathrm{CF}_{3}$ groups [24,30]. Similarly, the absorption peak of $-\mathrm{CF}_{2}$ and $-\mathrm{CF}_{3}$ groups appeared in the FTIR spectra of $\mathrm{Al}_{2} \mathrm{O}_{3}-\mathrm{PFOS}$ but without the peak at $1065 \mathrm{~cm}^{-1}$, which indicates that there was probably no chemical bonding between $\mathrm{Al}_{2} \mathrm{O}_{3}$ and PFOS, suggesting the physical adhesion between $\mathrm{Al}_{2} \mathrm{O}_{3}$ nanoparticles and PFOS.

\section{Wettability switching by UV illumination and heating}

Both $\mathrm{TiO}_{2}$-PFOS coated surfaces and $\mathrm{Al}_{2} \mathrm{O}_{3}$-PFOS coated surfaces were directly illuminated under a UV lamp at a working distance of $10 \mathrm{~mm}$, and the WCAs were recorded every $5 \mathrm{~min}$. The $\mathrm{TiO}_{2}-$ PFOS coated surface transitioned from superhydrophobicity to superhydrophilicity after only $10 \mathrm{~min}$ of UV exposure, while it took $90 \mathrm{~min}$ for $\mathrm{Al}_{2} \mathrm{O}_{3}$-PFOS surfaces to transition. Then the samples were heated at $150{ }^{\circ} \mathrm{C}$ for $90 \mathrm{~min}$, the property of superhydrophobicity was recovered for the $\mathrm{TiO}_{2}-\mathrm{PFOS}$ coated surface, while the $\mathrm{Al}_{2} \mathrm{O}_{3}$-PFOS coated surface remained superhydrophilic. A transition time of $10 \mathrm{~min}$ from superhydrophobic to superhydrophilic is much faster than
FTIR Graph of $\mathrm{TiO}_{2}$ and $\mathrm{TiO}_{2}$ - PFOS

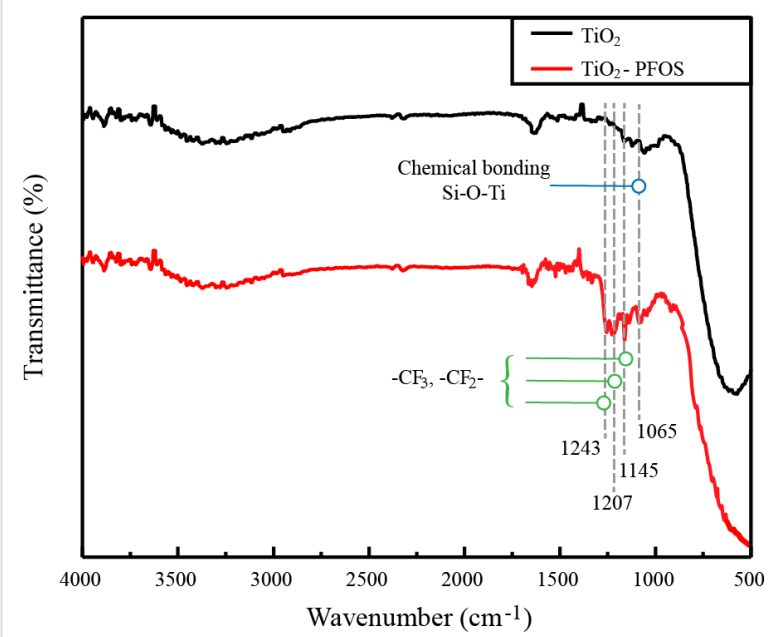

FTIR Graph of $\mathrm{Al}_{2} \mathrm{O}_{3}$ and $\mathrm{Al}_{2} \mathrm{O}_{3}$ - PFOS

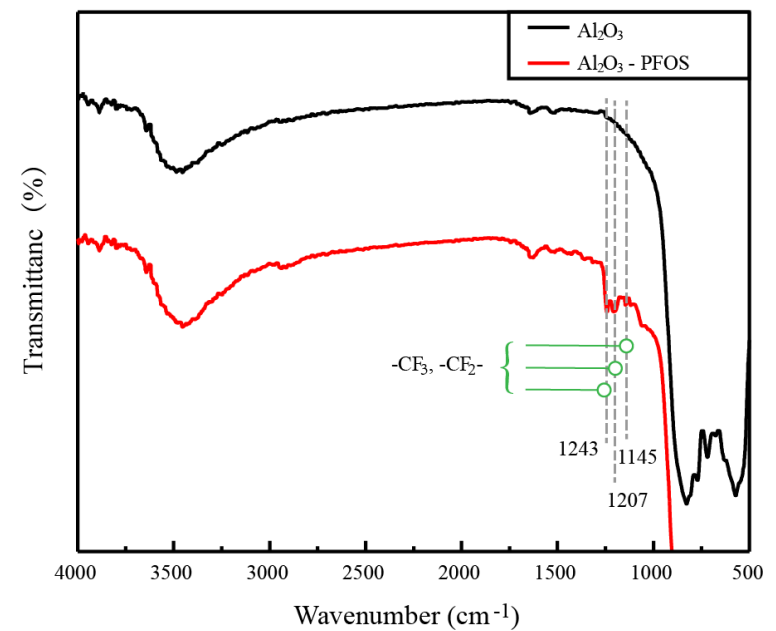

Figure 2: FTIR spectra of $\mathrm{TiO}_{2}$ and $\mathrm{TiO}_{2}-\mathrm{PFOS}, \mathrm{Al}_{2} \mathrm{O}_{3}$ and $\mathrm{Al}_{2} \mathrm{O}_{3}-\mathrm{PFOS}$. 
in previous works [22-27]. The samples in the process of wettability switching were observed by FTIR, as shown in Figure 3a. For the $\mathrm{TiO}_{2}-\mathrm{PFOS}$ surface, as the UV exposure time increases, the peak intensity at $1629 \mathrm{~cm}^{-1}$ and $3436 \mathrm{~cm}^{-1}$ (assigned to the bending vibration and stretching vibration of $-\mathrm{OH}$ groups, respectively) increased, while both peaks reduced after the heating treatment. At the same time, four peaks at $1207 \mathrm{~cm}^{-1}$, $1243 \mathrm{~cm}^{-1}, 2850 \mathrm{~cm}^{-1}$ and $2919 \mathrm{~cm}^{-1}$ (attributed to the bending vibration and stretching vibration of $-\mathrm{CF}_{2}$ - and $-\mathrm{CF}_{3}$ groups) undergo no obvious changes either under UV illumination or high temperature exposure. The change in transmittance for selected transitions are listed in Figure 3b, which shows that the change of $-\mathrm{OH}$ in $\mathrm{TiO}_{2}$ is much larger than the change of $-\mathrm{CF}_{2}-$ or $-\mathrm{CF}_{3}$ in PFOS. The change of $-\mathrm{CF}_{2}$ - or $-\mathrm{CF}_{3}$ can be observed after long time UV illumination as shown in Figure 4. Finally, PFOS was completely removed due to UV illumination and the chemical bonding between $\mathrm{TiO}_{2}$ and PFOS ( $\left.\mathrm{Si}-\mathrm{O}-\mathrm{Ti}\right)$ is without exception. The $\mathrm{Al}_{2} \mathrm{O}_{3}$-PFOS samples achieved the transition to super-wettability under UV illumination but required a much longer time of up to $90 \mathrm{~min}$. The bands at

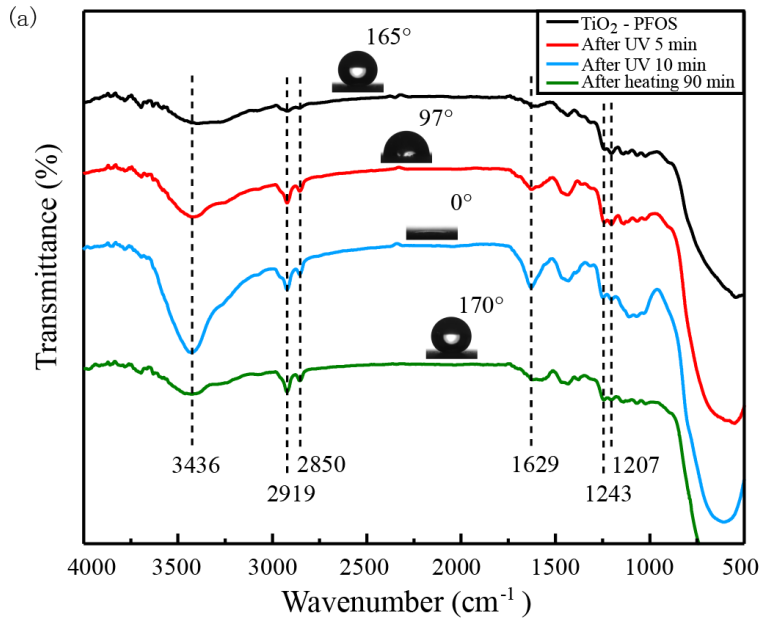

(b)

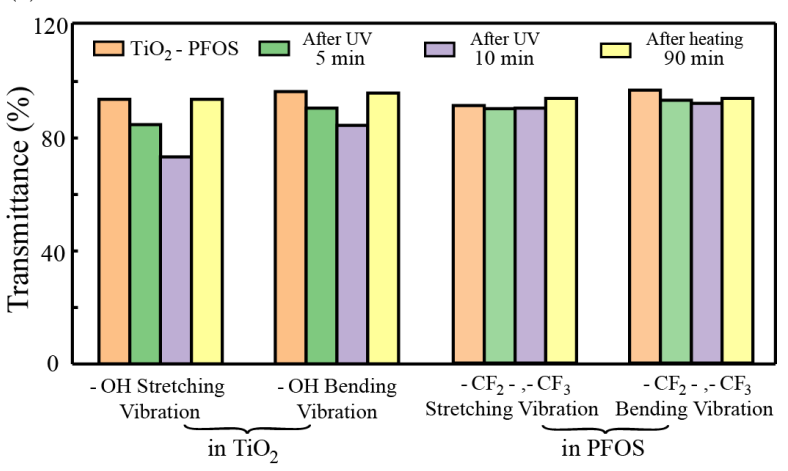

Figure 3: (a) Contact angle and FTIR spectrum of the $\mathrm{TiO}_{2}-\mathrm{PFOS}$ surface under different treatment conditions. (b) The change in transmittance for selected transitions, $-\mathrm{OH},-\mathrm{CF}_{2^{-}}$and $-\mathrm{CF}_{3}$.
$1210 \mathrm{~cm}^{-1}$ and $1240 \mathrm{~cm}^{-1}$ which represent the vibration of the $-\mathrm{CF}_{2}$ - and $-\mathrm{CF}_{3}$ groups in PFOS was not recovered, while the $-\mathrm{OH}$ vibration in $\mathrm{Al}_{2} \mathrm{O}_{3}$ experienced no significant change.

The wettability transition of $\mathrm{TiO}_{2}$ under UV illumination and heat treatment has been previously reported and was explained by the formation of $\mathrm{Ti}-\mathrm{O}-\mathrm{H}$ bonds under UV light, while heating of the surface results in the decrease in the concentration of Ti-O-H bonds [33,34]. As reported, due to the low band gap energy of $\mathrm{TiO}_{2}$, the photo-induced electron-hole pairs are generated on the $\mathrm{TiO}_{2}$ surfaces under UV illumination. The holes lead to the production of oxygen vacancies to enhance the adsorption of hydroxy groups, while the hydroxy groups are replaced by oxygen atoms that have a stronger bond on the defect sites during heating process. However, the change in $\mathrm{TiO}_{2}$ cannot fully explain the fast wettability transition of the $\mathrm{TiO}_{2}$-PFOS coated surface. Based on the data shown in Figure 3 and Figure 4 , the $-\mathrm{CF}_{2}$ - and $-\mathrm{CF}_{3}$ groups of PFOS were degraded and oxidized due to the high energy of UV illumination. The oxygen in the air stimulates a metastable state

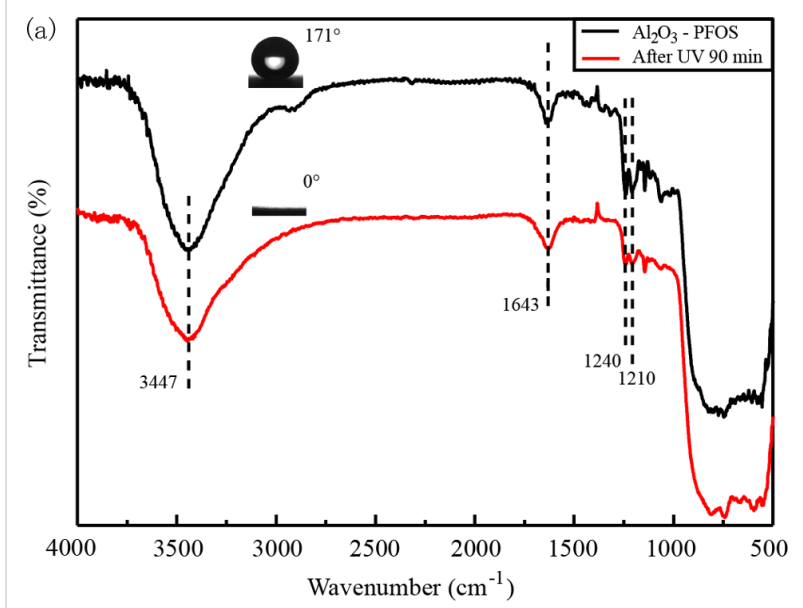

(b)

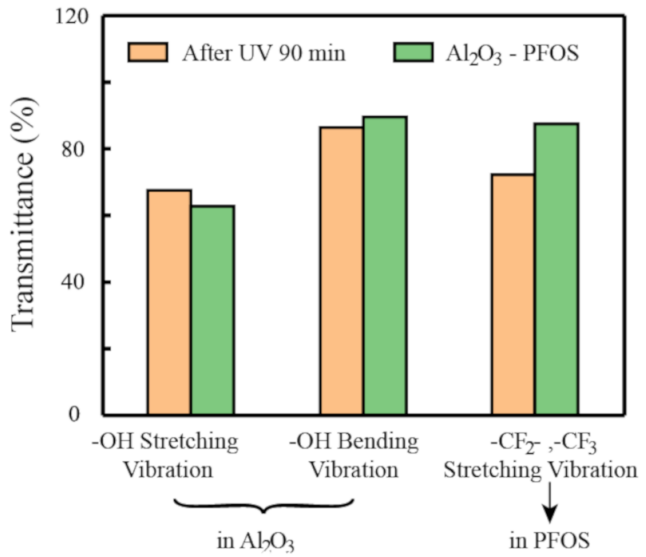

Figure 4: (a) Contact angle and FTIR spectrum of the $\mathrm{Al}_{2} \mathrm{O}_{3}-\mathrm{PFOS}$ surface under different treatment conditions. (b) The change in transmittance for selected transitions, $-\mathrm{OH},-\mathrm{CF}_{2^{-}}$and $-\mathrm{CF}_{3}$. 
which has a strong oxidizing property. In addition, the end of the fluorocarbon chains were changed into - $\mathrm{OH}$ groups which could decrease the WCA faster with increasing UV illumination time. It can thus be inferred that the oxidization of PFOS is due to UV illumination and the photocatalytic effect of $\mathrm{TiO}_{2}$ Unlike the changes occurring in $\mathrm{TiO}_{2}$, unfortunately, this change in PFOS is not reversible. The mechanism for the wettability transition of the $\mathrm{TiO}_{2}-\mathrm{PFOS}$ coated surface under UV illumination and heating treatment is shown in Figure 5. Since the change in PFOS is not reversible, the wettability transition cycles cannot continue indefinitely, and the surface will remain superhydrophilic when most of the $-\mathrm{CF}_{2}$ - and $-\mathrm{CF}_{3}$ groups are replaced by the $-\mathrm{OH}$ groups on PFOS. PFOS has a short carbon chain which can enhance the change of the $-\mathrm{CF}_{2}$ - and $-\mathrm{CF}_{3}$ groups and results in the much faster conversion time from superhydrophobicity to superhydrophilicity compared with the previous works $[35,36]$. The irreversible replacement of $-\mathrm{CF}_{2}-$ and $-\mathrm{CF}_{3}$ groups by $-\mathrm{OH}$ groups on $\mathrm{PFOS}$ was also confirmed by the wettability transition of the $\mathrm{Al}_{2} \mathrm{O}_{3}$-PFOS coated surfaces.

\section{Limitation of switchable cycles}

To further study the wettability switching of the surfaces, four samples comprised of a uniform weight of $\mathrm{TiO}_{2}$ modified by different concentrations of PFOS were sprayed onto the glass samples. All the coated surfaces were initially superhydrophobic. Then the coated samples were placed under UV illumination until they transitioned to superhydrophilic, and were thereafter heated in an air-dry oven until they recovered their superhydrophobic property - this cycle was repeated until the surfaces could no longer recover the superhydrophobic property. For each concentration of PFOS, five identical samples were prepared for statistical reliability. The experimental results are shown in Table 1, where it can be seen that the number of

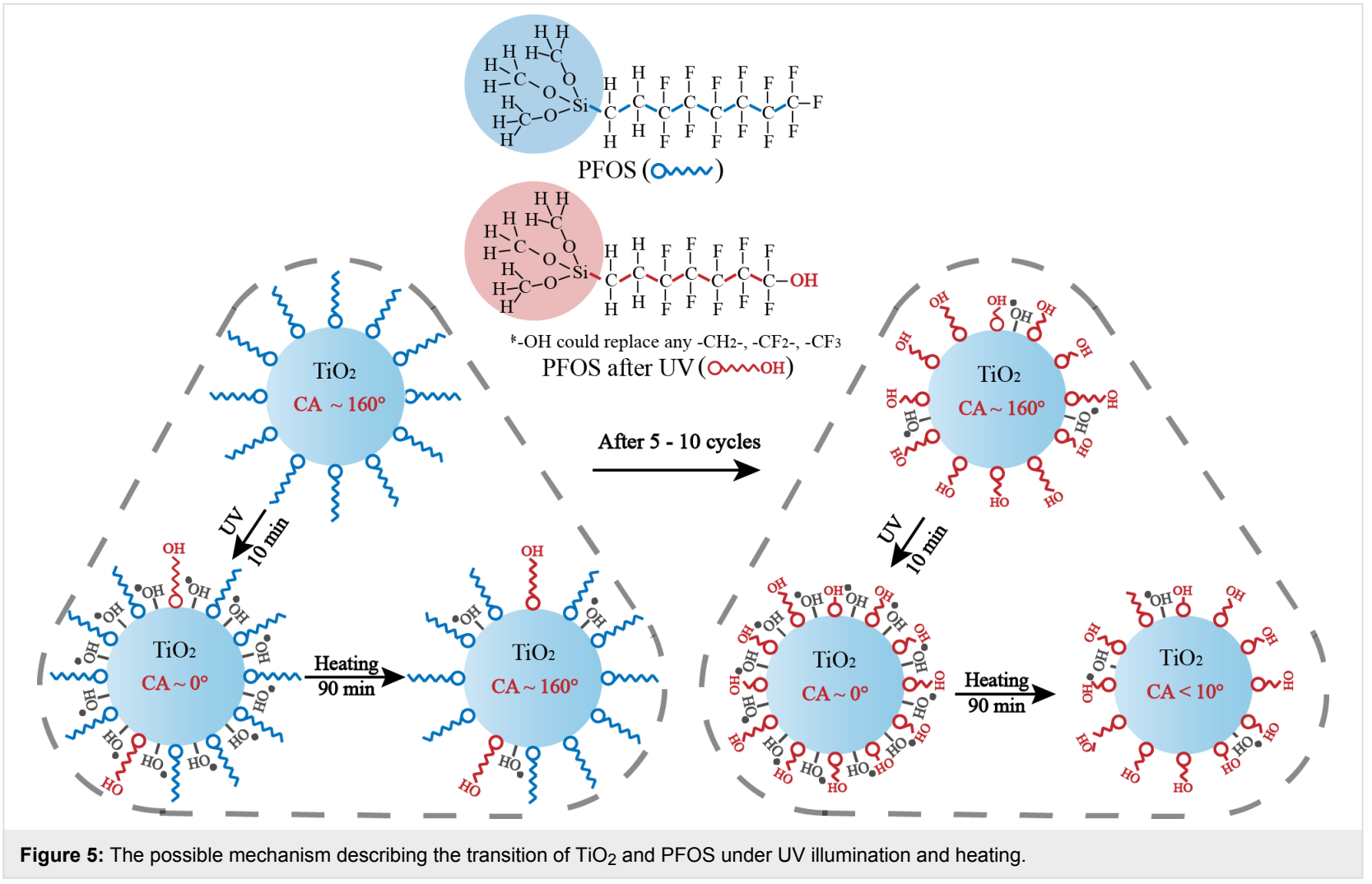

Table 1: Effect of PFOS concentration on the wettability conversion time and number of conversion cycles.

\begin{tabular}{lllll} 
Amount of PFOS in $50 \mathrm{~mL}$ ethanol $(\mathrm{g})$ & \multicolumn{2}{l}{ Initial contact angle $\left(^{\circ}\right)$} & $R_{\mathrm{a}}(\mu \mathrm{m})$ & Wettability conversion time (min) \\
\hline 0.5 & 169 & 2.334 & 5 & $0-1$ \\
1.0 & 171 & 2.627 & 10 & $2-3$ \\
1.5 & 172 & 2.550 & 30 & $5-6$ \\
2.0 & 168 & 2.877 & 60
\end{tabular}


cycles first increases with the concentration of PFOS, then decreases, while the switching time from superhydrophobic to superhydrophilic increases constantly with increasing PFOS concentration. This phenomena indicates that more PFOS can provide more $-\mathrm{CF}_{2-},-\mathrm{CF}_{3}$ and can initially increase the maximum number of conversion cycles. However, an excess of PFOS results in an increase in the time to achieve superhydrophilicity which enhances the amount of $-\mathrm{CF}_{2-},-\mathrm{CF}_{3}$ changed in one cycle, and subsequently decreases the number of possible cycles. As a result, to obtain a faster wettability transition time as well as a larger number of conversion cycles, an appropriate amount of PFOS and $\mathrm{TiO}_{2}$ is needed. It should be noted that with the same concentration of PFOS, the total UV illumination time for the surface to transition to unrecovered superhydrophilicity for $\mathrm{TiO}_{2}-\mathrm{PFOS}$ and $\mathrm{Al}_{2} \mathrm{O}_{3}-\mathrm{PFOS}$ is $30 \mathrm{~min}$ and $90 \mathrm{~min}$, respectively. This indicates that the oxidization time of PFOS is increased by the photocatalytic effect of $\mathrm{TiO}_{2}$.

For the sample with $1.5 \mathrm{~g}$ PFOS, the CA of the six cycles and the images of the conversion processes in the first and the last cycles are shown in Figure 6. The transition time from superhydrophobic to superhydrophilic decreased from the first cycle to the last cycle. This can be explained by the unrecoverable dissociation of the $-\mathrm{CF}_{2}$ - and $-\mathrm{CF}_{3}$ groups, which is also in agreement with the proposed mechanism in Figure 5.

\section{Conclusion}

$\mathrm{TiO}_{2}$ nanoparticles modified with PFOS (which has relatively short carbon chains) were applied on glass substrates to achieve fast, switchable super-wettability, demonstrated by a WCA that could be recovered from $\approx 165^{\circ}$ to almost $0^{\circ}$. The experimental results show that the PFOS could reduce the conversion time from nearly $1 \mathrm{~h}$ to about $10 \mathrm{~min}$, and the superhydrophobicity of the surfaces could be recovered after heating for $90 \mathrm{~min}$ at $120^{\circ} \mathrm{C}$. However, it was shown that certain concentrations of PFOS limit the number of recovery cycles, whereby the optimal concentration of PFOS was identified to achieve about 5 to 10 cycles. The unrecoverable change of the $-\mathrm{CF}_{2}-$ and $-\mathrm{CF}_{3}$ groups on PFOS and the recoverable change of $-\mathrm{OH}$ groups on $\mathrm{TiO}_{2}$ were recorded by FTIR. These effects can explain both the shorter transition time and the limitation that (initially) the change of the $-\mathrm{CF}_{2}$ - and $-\mathrm{CF}_{3}$ groups leads to a quicker conversion time from superhydrophobicity to superhydrophilicity. However, this is only true when most of the $-\mathrm{CF}_{2}-$ and $-\mathrm{CF}_{3}$ groups are changed unrecoverably, and the whole surface cannot not transition back to a superhydrophobic state.

\section{Experimental}

\section{Materials and chemicals}

Titanium dioxide $\left(\mathrm{TiO}_{2}\right.$, rutile) with a diameter of $\approx 25 \mathrm{~nm}$ and aluminium dioxide $\left(\mathrm{Al}_{2} \mathrm{O}_{3}\right)$ with a diameter of $\approx 30 \mathrm{~nm}$ were
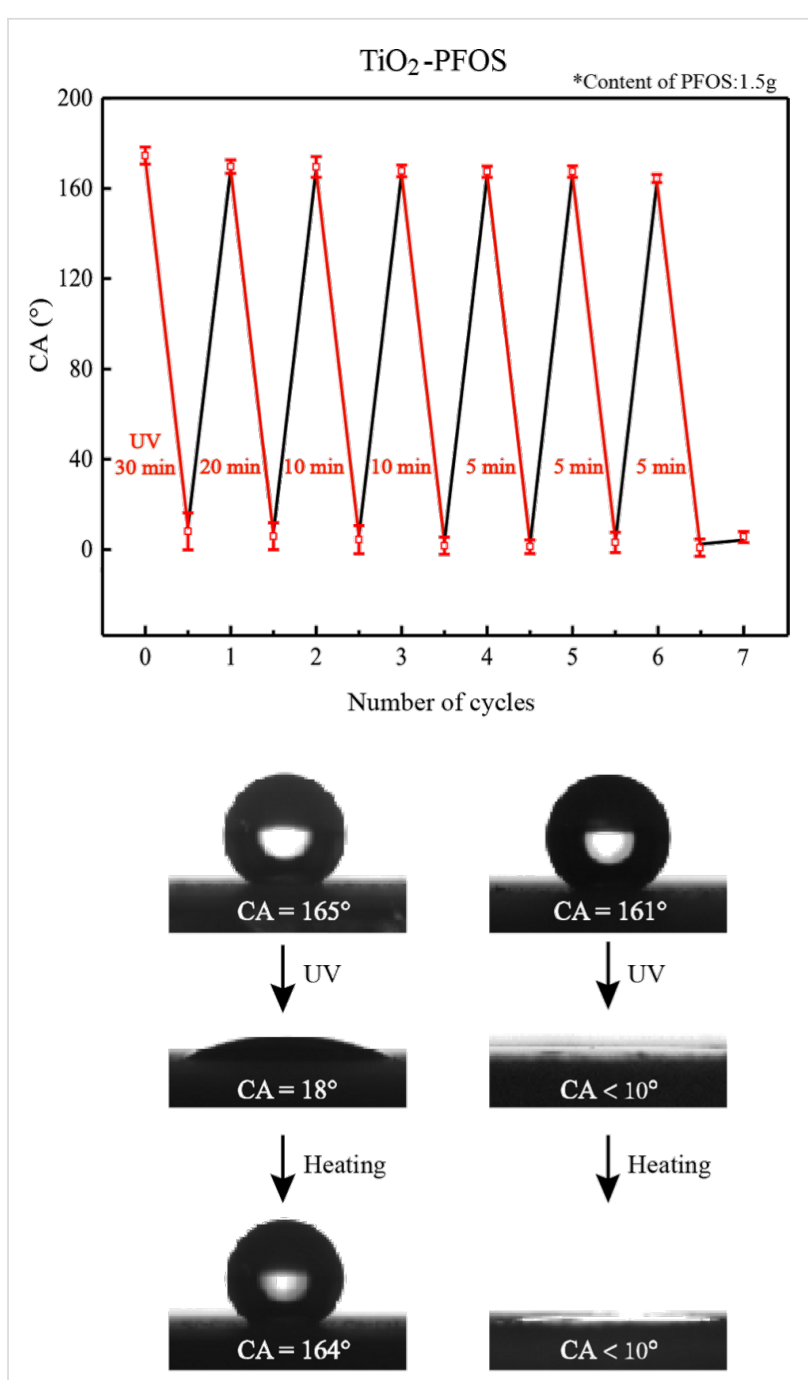

First Cycle

$\mathrm{CA}<10^{\circ}$

Last Cycle

Figure 6: Reversible superhydrophobic/superhydrophilic switching of the composite surface under UV illumination and heating (top), and the first and last cycle wettability switching process of a sample (bottom).

acquired from Shanghai Aladdin Bio-Chem Technology Corporation (Shanghai, China). $1 \mathrm{H}, 1 \mathrm{H}, 2 \mathrm{H}, 2 \mathrm{H}$-Perfluorooctyl(trimethoxy)silane (PFOS) was obtained from Shanghai Macklin Biochemical Corporation (Shanghai, China). Other chemicals include $99.9 \%$ ethanol used as the solvent and deionized water was used in the CA measurements.

\section{Preparation of coating surfaces}

Rutile phase $\mathrm{TiO}_{2}$ was modified by a simple hydrolysis reaction in order to obtain superhydrophobicity. In the modification process, $1 \mathrm{~g}$ of PFOS was dissolved into $50 \mathrm{~mL}$ ethanol and stirred for $1 \mathrm{~h}$ at ambient temperature in order to fully hydrolyse fluoroalkylsilane. Next, $3 \mathrm{~g}$ of rutile $\mathrm{TiO}_{2}$ was added into the solution and stirred for another $1 \mathrm{~h}$ to form the suspension. The suspension could be used to spray or paint a substrate with a 
spray gun $(20 \mathrm{kPa})$. When the surfaces were dried, the superhydrophobicity is revealed. $\mathrm{Al}_{2} \mathrm{O}_{3}$ was modified by the same method as $\mathrm{TiO}_{2}$.

\section{UV illumination and heating experiments}

A UV lamp (30 W) obtained from Cnlight Optical-Electrical Technology Corporation (Guangdong, China) was used to generate the UV illumination. The ultraviolet power density was set at $94 \mu \mathrm{W} / \mathrm{cm}^{2}$ and the wavelength was $254 \mathrm{~nm}$. The change of the WCA under UV light illumination was measured at short intervals. For the heating process, which was employed to recover the superhydrophobicity, the surface was heated in the air-dry oven at $150{ }^{\circ} \mathrm{C}$ for $90 \mathrm{~min}$ after UV illumination. The switching time from superhydrophilic to superhydrophobic was found to be reduced with increasing heating temperature.

\section{Characterization}

The microstructure of the coating surfaces was studied using scanning electron microscopy (SEM, ZEISS MERLIN Compact SEM, operated at a $20 \mathrm{kV}$ acceleration voltage, Carl Zeiss Jena, Germany), and the surface roughness was measured with a laser confocal microscope (LCM, OLS5000, Olympus, Japan). The chemical modification and the end group changes on the surfaces was studied by Fourier transform infrared spectroscopy (FTIR, Nicolet iS50, Thermo Scientific, USA). The contact angles were measured at room temperature with an optical contact angle meter (DropMeterTM Element A-60, Maist, Ningbo, China), where the static CAs of the droplets $(6 \mu \mathrm{L})$ placed onto the surfaces were measured five times at different locations.

\section{Acknowledgements}

This research was supported by the National Natural Science Foundation of China (Grant Nos. 51505108 and 51475118) and Key Laboratory of Micro-systems and Micro-structures Manufacturing of Ministry of Education, Harbin Institute of Technology (No. 2017KM009).

\section{ORCID ${ }^{\circledR}$ iDs}

Yunlu Pan - https://orcid.org/0000-0003-1836-7751

\section{References}

1. Israelachvili, J. N. Adhesion, Friction and Lubrication of Molecularly Smooth Surfaces. In Fundamentals of Friction: Macroscopic and Microscopic Processes; Singer, I. L.; Pollock, H. M., Eds.; NATO ASI Series (Series E: Applied Sciences), Vol. 220; Springer Netherlands: Dordrecht, Netherlands, 1992. doi:10.1007/978-94-011-2811-7_19

2. Bhushan, B. Biomimetics; Springer International Publishing: Cham, Switzerland, 2018. doi:10.1007/978-3-642-25408-6

3. Sun, Z.; Liao, T.; Liu, K.; Jiang, L.; Kim, J. H.; Dou, S. X. Small 2014, 10, 3001-3006. doi:10.1002/smll.201400516
4. Jin, X.; Shi, B.; Zheng, L.; Pei, X.; Zhang, X.; Sun, Z.; Du, Y.; Kim, J. H.; Wang, X.; Dou, S.; Liu, K.; Jiang, L. Adv. Funct. Mater. 2014, 24, 2721-2726. doi:10.1002/adfm.201304184

5. Wang, Y.; Ma, K.; Xin, J. H. Adv. Funct. Mater. 2018, 28, 1705128. doi:10.1002/adfm.201705128

6. Jeevanandam, J.; Barhoum, A.; Chan, Y. S.; Dufresne, A.; Danquah, M. K. Beilstein J. Nanotechnol. 2018, 9, 1050-1074. doi:10.3762/bjnano.9.98

7. Li, F.; Wang, Z.; Huang, S.; Pan, Y.; Zhao, X. Adv. Funct. Mater. 2018, 28, 1706867. doi:10.1002/adfm.201706867

8. Xu, Z.; Zhou, H.; Tan, S.; Jiang, X.; Wu, W.; Shi, J.; Chen, P. Beilstein J. Nanotechnol. 2018, 9, 508-519. doi:10.3762/bjnano.9.49

9. Sun, Z.; Liao, T.; Liu, K.; Jiang, L.; Kim, J. H.; Dou, S. X. Nano Res. 2013, 6, 726-735. doi:10.1007/s12274-013-0350-6

10. Bhushan, B., Ed. Springer Handbook of Nanotechnology; Springer Handbooks; Springer Berlin: Berlin, Germany, 2017. doi:10.1007/978-3-662-54357-3

11. Liang, C.; Wen, J.; Liao, X. Beilstein J. Nanotechnol. 2018, 9 , 1793-1801. doi:10.3762/bjnano.9.170

12. Dalei, J.; Shiyu, S.; Lei, H. Int. J. Heat Mass Transfer 2018, 128, 1344-1350. doi:10.1016/j.jheatmasstransfer.2018.08.006

13. Khongtong, S.; Ferguson, G. S. Langmuir 2004, 20, 9992-10000. doi:10.1021/la0497191

14. Muthiah, P.; Boyle, T. J.; Sigmund, W. Macromol. Mater. Eng. 2013, 298, 1251-1258. doi:10.1002/mame.201200411

15. Zhu, L.; Xu, J.; Xiu, Y.; Sun, Y.; Hess, D. W.; Wong, C.-P. J. Phys. Chem. B 2006, 110, 15945-15950. doi:10.1021/jp063265u

16. Zhang, G.; Duan, Z.; Wang, Q.; Li, L.; Yao, W.; Liu, C. Appl. Surf. Sci. 2018, 427, 628-635. doi:10.1016/j.apsusc.2017.08.082

17. Fujishima, A.; Zhang, X.; Tryk, D. A. Surf. Sci. Rep. 2008, 63, 515-582. doi:10.1016/j.surfrep.2008.10.001

18. Li, W.; Guo, T.; Meng, T.; Huang, Y.; Li, X.; Yan, W.; Wang, S.; Li, X. Appl. Surf. Sci. 2013, 283, 12-18. doi:10.1016/j.apsusc.2013.05.085

19. Awaja, F.; Gilbert, M.; Kelly, G.; Fox, B.; Pigram, P. J. Prog. Polym. Sci. 2009, 34, 948-968. doi:10.1016/j.progpolymsci.2009.04.007

20. Lai, Y.; Huang, J.; Cui, Z.; Ge, M.; Zhang, K.-Q.; Chen, Z.; Chi, L. Small 2016, 12, 2203-2224. doi:10.1002/smll.201501837

21. Wang, R.; Hashimoto, K.; Fujishima, A.; Chikuni, M.; Kojima, E.; Kitamura, A.; Shimohigoshi, M.; Watanabe, T. Nature 1997, 388 431-432. doi:10.1038/41233

22. Jin, C.; Yan, R.; Huang, J. J. Mater. Chem. 2011, 21, 17519-17525. doi:10.1039/c1jm13399c

23. Chagas, G. R.; Weibel, D. E. Polym. Bull. 2017, 74, 1965-1978. doi:10.1007/s00289-016-1817-x

24. Villafiorita Monteleone, F.; Caputo, G.; Canale, C.; Cozzoli, P. D.; Cingolani, R.; Fragouli, D.; Athanassiou, A. Langmuir 2010, 26, 18557-18563. doi:10.1021/la1026398

25. Ding, X.; Zhou, S.; Gu, G.; Wu, L. J. Mater. Chem. 2011, 21 , 6161-6164. doi:10.1039/c0jm04546b

26. Kong, Y.; Liu, Y.; Xin, J. H. J. Mater. Chem. 2011, 21, $17978-17987$. doi:10.1039/c1jm12516h

27. Sun, T.; Wang, G.; Feng, L.; Liu, B.; Ma, Y.; Jiang, L.; Zhu, D. Angew. Chem., Int. Ed. 2004, 43, 357-360. doi:10.1002/anie.200352565

28. Sawada, E.; Kakehi, H.; Chounan, Y.; Miura, M.; Sato, Y.; Isu, N.; Sawada, H. Composites, Part B 2010, 41, 498-502. doi:10.1016/j.compositesb.2010.04.002

29. Petroffe, G.; Wang, C.; Sallenave, X.; Sini, G.; Goubard, F.; Péralta, S. J. Mater. Chem. A 2015, 3, 11533-11542. doi:10.1039/c5ta01710f 
30. Qing, Y.; Yang, C.; Yu, N.; Shang, Y.; Sun, Y.; Wang, L.; Liu, C.

Chem. Eng. J. 2016, 290, 37-44. doi:10.1016/j.cej.2016.01.013

31. Ito, Y.; Heydari, M.; Hashimoto, A.; Konno, T.; Hirasawa, A.; Hori, S.;

Kurita, K.; Nakajima, A. Langmuir 2007, 23, 1845-1850.

doi:10.1021/la0624992

32. Liu, C. S.; Zheng, D. M.; Zhou, J. G.; Wan, Y.; Li, Z. W.

Mater. Sci. Forum 2011, 688, 102-106.

doi:10.4028/www.scientific.net/msf.688.102

33. Kumar, S. G.; Devi, L. G. J. Phys. Chem. A 2011, 115, 13211-13241. doi:10.1021/jp204364a

34. Nakata, K.; Fujishima, A. J. Photochem. Photobiol., C 2012, 13, 169-189. doi:10.1016/j.jphotochemrev.2012.06.001

35. Sugimura, H.; Ushiyama, K.; Hozumi, A.; Takai, O. Langmuir 2000, 16 , 885-888. doi:10.1021/la990953e

36. Hou, W.; Wang, Q. Langmuir 2009, 25, 6875-6879.

doi:10.1021/la900151y

\section{License and Terms}

This is an Open Access article under the terms of the Creative Commons Attribution License

(http://creativecommons.org/licenses/by/4.0). Please note that the reuse, redistribution and reproduction in particular requires that the authors and source are credited.

The license is subject to the Beilstein Journal of

Nanotechnology terms and conditions:

(https://www.beilstein-journals.org/bjnano)

The definitive version of this article is the electronic one which can be found at: doi:10.3762/bjnano.10.87 